\title{
Application of Phosphonium Ionic Liquids as Ion Carriers in Polymer Inclusion Membranes (PIMs) for Separation of Cadmium(II) and Copper(II) from Aqueous Solutions
}

\author{
Beata Pospiech ${ }^{1}$
}

Received: 14 February 2015/Accepted: 21 September 2015/Published online: 12 November 2015

(C) The Author(s) 2015. This article is published with open access at Springerlink.com

\begin{abstract}
Facilitated transport through polymer inclusion membranes (PIMs) is a promising method for simultaneous separation and removal of valuable and toxic metal ions from aqueous solutions. Recently, ionic liquids (ILs) have been used as extracting agents for metal ions due to their unique physicochemical properties. This paper presents research on the facilitated transport of cadmium(II) and copper(II) ions from aqueous chloride solutions through PIMs with phosphonium ILs as new selective ion carriers. Cellulose triacetate membranes containing $o$-nitrophenyl octyl ether (ONPOE) as a plasticizer and Cyphos IL 101 [trihexyl(tetradecyl)phosphonium chloride] or Cyphos IL 104 [trihexyl(tetradecyl)phosphonium bis(2,4,4-trimethylpentyl)phosphinate] as the ion carriers have been prepared and applied for investigations. Cd(II) ions were transported preferably from hydrochloric acid solutions containing $\mathrm{Cu}(\mathrm{II})$ ions through the PIMs. Higher selectivity coefficient of $\mathrm{Cd}(\mathrm{II})$ over $\mathrm{Cu}(\mathrm{II}) \quad\left(S_{\mathrm{Cd} / \mathrm{Cu}}\right)$ from $0.1 \mathrm{~mol} \cdot \mathrm{dm}^{-3}$ hydrochloric acid was obtained for PIM with Cyphos IL 104 as the ion carrier. The influence of $\mathrm{HCl}$ and $\mathrm{NaCl}$ concentrations in the source phase on metal ion transport across PIM doped with Cyphos 104 was studied. It was found that the initial fluxes of Cd(II) and $\mathrm{Cu}$ (II) increase with increasing chloride ions concentration in the source phase. The selectivity coefficient for $\mathrm{Cd}(\mathrm{II})$ over $\mathrm{Cu}$ (II) decreases with increasing $\mathrm{HCl}$ concentration in the source phase. The results suggest that the separation system presented in this paper can be useful for the removal of $\mathrm{Cd}(\mathrm{II})$ from acidic chloride solutions in the presence of $\mathrm{Cu}$ (II).
\end{abstract}

Keywords Cadmium(II) · Copper(II) · Cyphos IL 101 · Cyphos IL $104 \cdot$ Polymer inclusion membrane (PIM)

Beata Pospiech

b.pospiech@wip.pcz.pl

1 Department of Chemistry, Czestochowa University of Technology, Armii Krajowej 19, 42-200 Czestochowa, Poland 


\section{Introduction}

Techniques for the separation of metal ions from industrial and waste solutions are extremely important in industrial applications. Increasing demand on metal production leads to research into efficient and economical methods for separation and recovery of metal ions [1,2]. Cadmium occurs as a minor constituent of base metal ores. Leach liquors of ores contain many valuable metals. Several technologies are used for selective removal of metals, including precipitation, solvent extraction, ion exchange, etc. [3]. Transport of metal ions from aqueous dilute solutions through liquid membranes was established as an alternative to other separation methods. Polymer inclusion membranes (PIMs) are a type of liquid membrane (LMs). PIMs usually contains a polymer support, an ion carrier and a plasticizer. The base polymer provides mechanical strength to the membrane. Plasticizer improves the flexibility and transport properties of the membrane. Moreover, plasticizer is also a solvent for an ion carrier, which is an extracting agent. It is worth highlighting that the volumes of organic solutions (carriers, plasticizers, ion carriers) which are needed for synthesis of PIMs are very low [4, 5]. $O$-nitrophenyl octylether (ONPOE) was used as plasticizer in this study because this compound shows remarkable physicochemical properties, including: a high dielectric constant, low solubility in water and low toxicity [6]. Moreover it acts as a good organic solvent for carrier molecules and improves the membranes softness and flexibility [7]. The choice of plasticizer influences the separation properties of the prepared membranes because the transport flux of metal ions depends strongly on the chemical nature of the plasticizer [8]. The selectivity and efficiency of transport processes depend on the polarity and viscosity of the plasticizers. Increasing the viscosity of the plasticizer decreases the rate of transport. Plasticizers with high polarity can be used preferentially as solvents in membranes [9]. Kebiche-Senhadji et al. [10] reported that the dielectric constant influences the balance between the efficiency of association and disassociation for the uptake of the metal ions by the ion carrier and its release from the complex metal-ion carrier at the receiving interface.

Cellulose triacetate (CTA) based membranes show good potential for industrial separation techniques due to high chemical stability and mechanical resistance, ease of synthesis, reduced consumption of reagents and high process selectivity $[11,12]$.

The transport of heavy metals from aqueous solutions, across PIMs, has been the subject of many investigations. PIMs, which are used for removal of metal ions contain different compounds as ion carriers, such as: di(2-ethylhexyl) phosphoric acid (D2EHPA) [11-13], thiophosphinic oxide (TOPO) [11, 14], Cyanex 301 [di(2,4,4-trimethylpentyl) dithiophosphinic acid] [15], Cyanex 471X (triisobutylphosphine sulphide) [16, 17], Aliquat 336 (trioctylmethylammonium chloride) [18-21], TOA (trioctylamine) [3], TIOA (triisoctylamine) [22], etc.

Recently, ionic liquids (ILs) have been used as extractants or ion carriers for metal ions from aqueous solutions. ILs exhibit many unique properties, such as: negligible vapor pressure, high thermal stability, non-flammability and good extractability for various organic compounds as well as for metal ions [23, 24]. Room temperature ionic liquids (RTILs) are an alternative to replace organic solvents because they are able to dissolve both polar and nonpolar compounds. The important advantage of ILs is their negligible vapor pressure, which results in lower emissions as well as their good chemical and thermal stabilities. Therefore, ionic liquids are considered as environmental friendly as well as low toxicity green solvents solvents as compared to volatile organic solvents [25-27]. 
Nowadays, an increasing interest in technologies of PIMs containing ILs can be observed [28-31]. Cyphos IL 101 and Cyphos IL 104 were used as extractants and ion carriers of $\mathrm{Zn}(\mathrm{II})$ and $\mathrm{Fe}(\mathrm{II})$ from aqueous chloride solutions [28, 29]. Zn(II) extraction from the feed containing $5 \mathrm{~g} \cdot \mathrm{dm}^{-3}$ exceeds $85 \%$; meanwhile, Fe(II) extraction was only $20 \%$ [28]. Transport process of $\mathrm{Zn}$ (II) and Fe(III) ions through a PIM with Cyphos IL 101 was relatively slow. Conversely, much more efficient transport through a PIM was observed for Fe(III) than $\mathrm{Zn}$ (II) [29]. Kogelnig et al. [30] reported results of the transport of $\mathrm{Zn}$ (II) from aqueous solution using PIMs based on poly(vinyl chloride) containing Cyphos IL 101. Zn(II) was efficiently extracted from $5 \mathrm{~mol} \cdot \mathrm{dm}^{-3} \mathrm{HCl}$ through membrane containing 30 wt.\% Cyphos 101, whereas back-extraction was successfully achieved with $1 \mathrm{~mol} \cdot \mathrm{dm}^{-3} \mathrm{H}_{2} \mathrm{SO}_{4}$ [29]. Removal of $\mathrm{Cr}(\mathrm{VI})$ ions from hydrochloric acid solutions using PIMs with Cyphos 104 has been studied by Guo et al. [31]. Polyvinylidene fluoride (PVDF) was used as polymeric support of these membranes and $\left[\mathrm{C}_{8} \mathrm{mim}\right]\left[\mathrm{BF}_{4}\right]$ as plasticizer. The maximum permeability coefficient $(P)$ was $9.64 \mu \mathrm{m} \cdot \mathrm{s}^{-1}$.

Separation of $\mathrm{Cd}(\mathrm{II})$ and $\mathrm{Cu}(\mathrm{II})$ from hydrochloric acid solutions by transport through PIMs with phosphonium ionic liquids as ion carriers has not been reported. The aim of the present work is to study the facilitated transport of $\mathrm{Cd}$ (II) and $\mathrm{Cu}(\mathrm{II})$ across PIMs with Cyphos IL 101 and Cyphos IL 104. The permeation of the metal ions is investigated as a function of various experimental variables: concentration of hydrochloric acid and sodium chloride in the source phase, carrier concentration in the membrane, etc. The transport selectivity of $\mathrm{Cd}(\mathrm{II})$ and $\mathrm{Cu}$ (II) from hydrochloric acid and sodium chloride solutions was also investigation.

\section{Experimental}

\subsection{Reagents}

Cadmium(II) chloride $\left(\mathrm{CdCl}_{2} \cdot 2.5 \mathrm{H}_{2} \mathrm{O}, 99 \%\right)$, copper(II) chloride $\left(\mathrm{CuCl}_{2} \cdot 2 \mathrm{H}_{2} \mathrm{O}, 99 \%\right)$, sodium chloride $(\mathrm{NaCl})$, hydrochloric acid $(\mathrm{HCl})$, and sulfuric acid $\left(\mathrm{H}_{2} \mathrm{SO}_{4}\right)$ were of analytical grade and were purchased from POCh (Gliwice, Poland). Aqueous solutions were prepared with deionized water.

Trihexyl(tetradecyl)phosphonium chloride (Cyphos ${ }^{\circledR}$ IL 101) and trihexyl(tetradecyl)phosphonium bis(2,4,4-trimethylpentyl)phosphinate (Cyphos ${ }^{\circledR}$ IL 104) of $95 \%$ purity were purchased from Cytec Canada Industries Inc.; CTA, dichloromethane, toluene, and $o$-nitrophenyl octyl ether (ONPOE) were of analytical reagent grade (Aldrich) and used without further purification. The density of the plasticizer, ONPOE, is $1.041 \mathrm{~g} \cdot \mathrm{cm}^{-3}$.

\subsection{Polymer Inclusion Membrane}

The membranes were prepared as described elsewhere [16-18]. Solutions of CTA, the ion carrier (Cyphos IL 101, Cyphos IL 104), and the plasticizer [o-nitrophenyl octyl ether (ONPOE)] were prepared in dichloromethane. A portion of this solution was poured on a flat-bottom glass Petri dish which was kept on a leveled surface. The organic solvent was allowed to evaporate for $12 \mathrm{~h}$. The resultant membrane was peeled off from the Petri dish and this membrane was washed with water and equilibrated in distillated water before use. 


\subsection{Transport Experiments}

Transport experiments were carried out in the experimental setup of PIM system described in the earlier papers [16-18]. The volumes of source and receiving phases were $100 \mathrm{~cm}^{3}$, respectively. The effective membrane area, which was exposed to both phases, was $12.56 \mathrm{~cm}^{2}$. Both the source and receiving aqueous phases were stirred using a magnetic stirrer. To transport $\mathrm{Cd}$ (II) and $\mathrm{Cu}$ (II) across the PIM, a membrane module was used to which both aqueous phases were pumped with a peristaltic pump (PP1B-05A type, Zalimp, Poland) working at a speed of $100 \mathrm{~cm}^{3} \cdot \mathrm{min}^{-1}$ from tanks containing source and receiving phases, respectively. The schematic diagram of the experimental setup of PIM system has been shown in the earlier paper [16]. The permeation of metal ions was monitored by sampling of the source phase, which was analyzed by an atomic absorption spectrophotometer (Solaar 939, Unicam).

The kinetics of PIM transport processes is described by a first-order reaction in metal ion concentration $[16,17]$ :

$$
\ln \left(\frac{c}{c_{i}}\right)=-k t
$$

where $c$ is the metal ion concentration in the source phase at some given time, $c_{i}$ is the initial metal ion concentration in the source phase, $k$ is the rate constant, and $t$ is the time of transport.

To calculate the $k$ value, a plot of $\ln \left(c / c_{i}\right)$ versus time was prepared. The rate constant value for the duplicate transport experiment was then averaged and standard deviation was calculated. The permeability coefficient $(P)$ was calculated as follows:

$$
P=\frac{V}{A} k
$$

where $V$ is volume of the aqueous source phase, and $A$ is the effective area of membrane.

The initial flux $\left(J_{i}\right)$ was determined as:

$$
J_{i}=P \cdot c_{i}
$$

The selectivity coefficient $(S)$ is defined as the ratio of initial fluxes for $\mathrm{M}_{1}$ and $\mathrm{M}_{2}$ metal ions, respectively:

$$
S=\frac{J_{i, M_{1}}}{J_{i, M_{2}}}
$$

The recovery factor $(R F)$ of metal ions from the source phase into the receiving phase was calculated as:

$$
R F=\frac{c_{i}-c}{c_{i}} \cdot 100 \%
$$

\subsection{Solvent Extraction}

Solvent extraction was carried out as reported earlier [18, 32]. Equal volumes of organic and aqueous phases (phase volume ratio $\mathrm{O} / \mathrm{A}=1$ ) were mechanically shaken for $20 \mathrm{~min}$ at $25 \pm 2{ }^{\circ} \mathrm{C}$. After settling, the aqueous phase was separated from the organic phase. The equilibrium $\mathrm{pHs}$ of the aqueous phases were measured with an Elmetron CX-731 pH-meter 
equipped with a glass electrode (Hydromet, Poland). Metal ion concentrations in the aqueous phases were determined with an AAS Solaar 939 (Unicam) atomic absorption spectrophotometer. The concentrations of metal ions in the aqueous phases were determined before and after solvent extraction to allow calculation of the extraction efficiency and after stripping to calculate the stripping efficiency. The concentrations of metals in the organic phases were calculated by mass balance. Each experiment was carried out three times and the error did not exceed $5 \%$. Distribution ratio $(D)$ and extraction efficiency $(\% E)$ are defined as follows:

$$
\begin{gathered}
D=\frac{[\mathbf{M}]_{\mathrm{org}}}{[\mathrm{M}]_{\mathrm{aq}}} \\
\% E=\frac{D}{D+10} \cdot 100 \%
\end{gathered}
$$

where $[\mathrm{M}]_{\text {org }}$ and $[\mathrm{M}]_{\mathrm{aq}}$ denote metal concentrations in the organic and aqueous phases after solvent extraction, respectively.

The electivity coefficient $\left(S_{\mathrm{M} 1 / \mathrm{M} 2}\right)$ for $\mathrm{M}_{1}$ over $\mathrm{M}_{2}$ was calculated as follows:

$$
S_{M 1 / M 2}=\frac{D_{M 1}}{D_{M 2}}
$$

\subsection{Stripping Experiments}

To evaluate the stripping efficiency of sulfuric acid, the extraction solvent was first contacted with an aqueous solution containing $0.01 \mathrm{~mol} \cdot \mathrm{dm}^{-3} \mathrm{Cd}(\mathrm{II})$ and $0.01 \mathrm{~mol} \cdot \mathrm{dm}^{-3}$ $\mathrm{Cu}(\mathrm{II})$ in $0.1 \mathrm{~mol} \cdot \mathrm{dm}^{-3} \mathrm{HCl}$ with $0.1 \mathrm{~mol} \cdot \mathrm{dm}^{-3}$ Cyphos IL 101 and $0.1 \mathrm{~mol} \cdot \mathrm{dm}^{-3}$ Cyphos IL 104, respectively, at a phase volume ratio $\mathrm{O}: \mathrm{A}=1$. After settling, the organic phase was separated from aqueous phase. The organic phase was then put in contact with the stripping solution (sulfuric acid solution) at phase volume ratio $\mathrm{O}: \mathrm{A}=1$ at $25 \pm 2{ }^{\circ} \mathrm{C}$. After shaking, the organic and aqueous phases were separated and the metal concentrations in the aqueous phases were determined by AAS to calculate the stripping efficiency.

\section{Results and Discussion}

\subsection{Solvent Extraction of $\mathrm{Cd}(\mathrm{II})$ and $\mathrm{Cu}(\mathrm{II})$ from $\mathrm{HCl}$ Solutions}

The selective extraction of $\mathrm{Cd}(\mathrm{II})$ and $\mathrm{Cu}$ (II) from hydrochloric acid solutions is difficult because both metal ions exist as anionic chloride complexes at high chloride concentration. Copper chloride complexes seem to have the same extractability as cadmium chloride complexes. The phosphonium ILs, such as: Cyphos IL 101 and Cyphos IL 104 have been chosen for the separation process of $\mathrm{Cd}(\mathrm{II})$ and $\mathrm{Cu}$ (II) because these salts differ by anions that can affect extraction properties of these ILs. Cyphos IL 101 contains a hydrophilic chloride anion, while Cyphos IL 104 is a derivative of Cyanex 272 and contains bis(2,4,4trimethylpentyl)phosphinate anion. To better understand the transport behavior of Cd(II) and $\mathrm{Cu}$ (II) from hydrochloric acid solutions through PIMs with Cyphos IL 101 and Cyphos Il 104 as the ion carriers, it was necessary to perform solvent extraction studies with the ionic liquids as extractants. To investigate the influence of hydrochloric acid concentration 
in the aqueous phase on the extraction efficiency of metal ions, the experiments were performed at different concentration of this acid. The concentration of $\mathrm{HCl}$ varied from 0.1 to $6 \mathrm{~mol} \cdot \mathrm{dm}^{-3}$. Figure 1 shows the effect of $\mathrm{HCl}$ concentration on the extraction efficiency of $\mathrm{Cd}(\mathrm{II})$ and $\mathrm{Cu}(\mathrm{II})$ by $0.1 \mathrm{~mol} \cdot \mathrm{dm}^{-3}$ Cyphos IL 101 and $0.1 \mathrm{~mol} \cdot \mathrm{dm}^{-3}$ Cyphos IL 104 in toluene, respectively. As can be seen from this figure, the extraction efficiency of $\mathrm{Cd}(\mathrm{II})$ was very high at all $\mathrm{HCl}$ concentrations with Cyphos IL 101 and Cyphos IL 104 and reached $99.9 \%$ independent of the $\mathrm{HCl}$ concentration. The extraction efficiency of $\mathrm{Cu}$ (II) increased with $\mathrm{HCl}$ concentration increasing up to $5 \mathrm{~mol} \cdot \mathrm{dm}^{-3} \mathrm{HCl}$, and then decreased for higher $\mathrm{HCl}$ concentrations (Fig. 1). As can be observed, the highest extraction efficiency of $\mathrm{Cu}$ (II) was $90.1 \mathrm{vol} \%$ from $5 \mathrm{~mol} \cdot \mathrm{dm}^{-3} \mathrm{HCl}$ by $0.1 \mathrm{~mol} \cdot \mathrm{dm}^{-3}$ Cyphos IL 101 in toluene.

The logarithm of the selectivity coefficient $\left(\log _{10} S_{\mathrm{Cd} / \mathrm{Cu}}\right)$ obtained with Cyphos 101 as well as by $0.1 \mathrm{~mol} \cdot \mathrm{dm}^{-3}$ Cyphos 104 in toluene decreases when the $\mathrm{HCl}$ concentration increases in the range from 0.1 to $5 \mathrm{~mol} \cdot \mathrm{dm}^{-3}$, as is shown in Fig. 2. The logarithm of the selectivity coefficient $\left(\log _{10} S_{\mathrm{Cd} / \mathrm{Cu}}\right)$ slightly increased for both extractants at $6 \mathrm{~mol} \cdot \mathrm{dm}^{-3}$ $\mathrm{HCl}$. The selectivity coefficients for $\mathrm{Cd}(\mathrm{II})$ over $\mathrm{Cu}$ (II) with Cyphos 104, depending on $\mathrm{HCl}$ concentration, are higher than those obtained with Cyphos 101. We can find in the literature that quaternary phosphonium salts can extract both neutral and anionic complexes [28, 29]. Extraction of $\mathrm{Cd}(\mathrm{II})$ and $\mathrm{Cu}(\mathrm{II})$ by Cyphos IL 101 and Cyphos IL 104 probably proceeds by different mechanisms depending on the acid and chloride concentrations in the aqueous phase. The extraction efficiency of Cd(II) by Cyphos IL 104 is very high and independent of $\mathrm{HCl}$ concentration in the aqueous solutions. We know that in

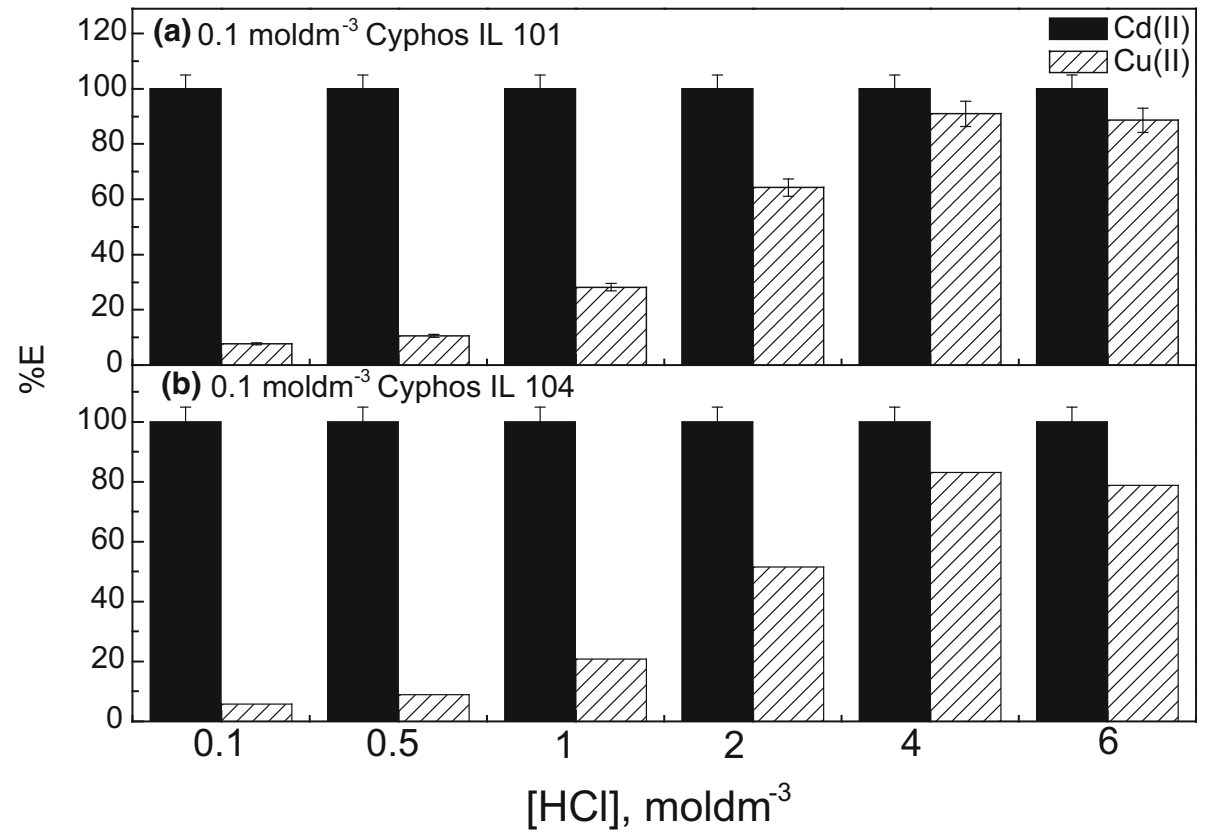

Fig. 1 Extraction efficiency of $\mathrm{Cd}(\mathrm{II})$ and $\mathrm{Cu}(\mathrm{II})$ as a function of $\mathrm{HCl}$ concentration by ILs. a $0.1 \mathrm{~mol} \cdot \mathrm{dm}^{-3}$ Cyphos IL 101 in toluene; b $0.1 \mathrm{~mol} \cdot \mathrm{dm}^{-3}$ Cyphos IL 104 in toluene. Aqueous phase: $0.01 \mathrm{~mol} \cdot \mathrm{dm}^{-3} \mathrm{Cd}$ (II) and $0.01 \mathrm{~mol} \cdot \mathrm{dm}^{-3} \mathrm{Cu}(\mathrm{II})$ in $\mathrm{HCl}$ solutions 


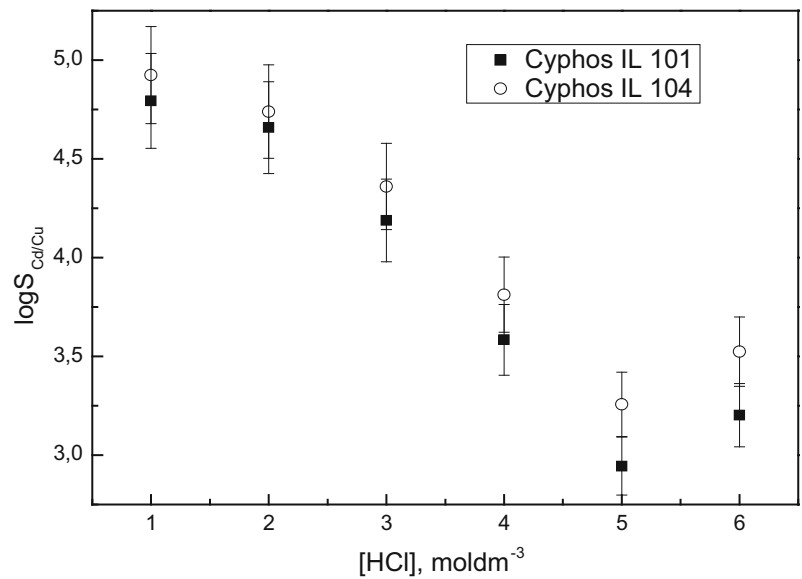

Fig. 2 Logarithm of selectivity coefficient $\left(\log _{10} S_{\mathrm{Cd} / \mathrm{Cu}}\right)$ of $\mathrm{Cd}(\mathrm{II})$ over $\mathrm{Cu}$ (II) versus $\mathrm{HCl}$ concentration. Aqueous phase: $0.01 \mathrm{~mol} \cdot \mathrm{dm}^{-3} \mathrm{Cd}(\mathrm{II}), 0.01 \mathrm{~mol} \cdot \mathrm{dm}^{-3} \mathrm{Cu}(\mathrm{II})$ in $\mathrm{HCl}$; organic phase: $0.1 \mathrm{~mol} \cdot \mathrm{dm}^{-3} \mathrm{Cyphos}$ IL 101 and $0.1 \mathrm{~mol} \cdot \mathrm{dm}^{-3}$ Cyphos IL 104 in toluene

chloride solutions cadmium(II) forms the cationic chlorocomplex $\mathrm{CdCl}^{+}$as well as stable complexes of the type $\mathrm{CdCl}_{2}$ and $\mathrm{CdCl}_{3}^{-}$at high chloride ions concentrations (Table 3). The extraction results suggest that not only an anion exchange mechanism of extraction occurs by Cyphos IL 104, because Cd(II) does not form stable anionic chlorocomplexes in $0.1 \mathrm{~mol} \cdot \mathrm{dm}^{-3} \mathrm{HCl}$. The proposed mechanism is given by the following equations:

Cyphos IL 104

$$
\begin{gathered}
\mathrm{Cd}_{\mathrm{aq}}^{2+}+2 \mathrm{Cl}_{\mathrm{aq}}^{-}+2 \mathrm{R}_{3} \mathrm{R}^{\prime} \mathrm{PA} \rightleftharpoons 2 \mathrm{R}_{3} \mathrm{R}^{\prime} \mathrm{PCl}_{\text {org }}+\mathrm{CdA}_{2 \text { org }} \\
\mathrm{CdCl}_{\mathrm{aq}}^{+}+\mathrm{Cl}_{\mathrm{aq}}^{-}+2 \mathrm{R}_{3} \mathrm{R}^{\prime} \mathrm{PA}_{\text {org }} \rightleftharpoons 2 \mathrm{R}_{3} \mathrm{R}^{\prime} \mathrm{PCl}_{\text {org }}+\mathrm{CdA}_{2 \text { org }} \\
\mathrm{CdCl}_{2 \mathrm{org}}+2 \mathrm{R}_{3} \mathrm{R}^{\prime} \mathrm{PA}_{\text {org }} \rightleftharpoons 2 \mathrm{R}_{3} \mathrm{R}^{\prime} \mathrm{PCl}_{\text {org }}+\mathrm{CdA}_{2 \text { org }} \\
\mathrm{H}_{\mathrm{aq}}^{+}+\mathrm{CdCl}_{3 \mathrm{aq}}^{-}+\mathrm{R}_{3} \mathrm{R}^{\prime} \mathrm{PA}_{\text {org }} \rightleftharpoons \mathrm{R}_{3} \mathrm{R}^{\prime} \mathrm{PCdCl}_{3 \text { org }}+\mathrm{HA}_{\text {org }} \\
\mathrm{CuCl}_{2 \mathrm{aq}}+2 \mathrm{R}_{3} \mathrm{R}^{\prime} \mathrm{PA}_{\text {org }} \rightleftharpoons 2 \mathrm{R}_{3} \mathrm{R}^{\prime} \mathrm{PCl}_{\text {org }}+\mathrm{CuA}_{2 \text { org }} \\
2 \mathrm{H}_{\mathrm{aq}}^{+}+\mathrm{CdCl}_{4 \mathrm{aq}}^{2-}+\mathrm{R}_{3} \mathrm{R}^{\prime} \mathrm{PA}_{\text {org }} \rightleftharpoons \mathrm{R}_{3} \mathrm{R}^{\prime} \mathrm{PHCdCl}_{4 \mathrm{org}}+\mathrm{HA}_{\text {org }}
\end{gathered}
$$

where A denotes the bis(2,4,4-trimethylpentyl)phosphinate anion, subscripts (aq) and (org) stand for the aqueous and organic phases, respectively.

Cyphos IL 101

$$
\begin{gathered}
\mathrm{CdCl}_{\mathrm{aq}}^{+}+\mathrm{Cl}_{\mathrm{aq}}^{-}+2 \mathrm{R}_{3} \mathrm{R}^{\prime} \mathrm{PCl}_{\mathrm{org}} \rightleftharpoons\left(\mathrm{R}_{3} \mathrm{R}^{\prime} \mathrm{P}\right)_{2} \mathrm{CdCl}_{4 \mathrm{org}} \\
\mathrm{CdCl}_{3 \mathrm{aq}}^{-}+\mathrm{R}_{3} \mathrm{R}^{\prime} \mathrm{PCl}_{\text {org }} \rightleftharpoons \mathrm{R}_{3} \mathrm{R}^{\prime} \mathrm{PCdCl}_{3 \text { org }}^{-}+\mathrm{Cl}_{\mathrm{aq}}
\end{gathered}
$$




$$
\begin{gathered}
\mathrm{CdCl}_{4 \mathrm{aq}}^{2-}+2 \mathrm{R}_{3} \mathrm{R}^{\prime} \mathrm{PCl}_{\text {org }} \rightleftharpoons\left(\mathrm{R}_{3} \mathrm{R}^{\prime} \mathrm{P}\right)_{2} \mathrm{CdCl}_{4 \text { org }}^{2-}+2 \mathrm{Cl}_{\text {org }}^{-} \\
\mathrm{CdCl}_{2 \mathrm{aq}}+2 \mathrm{R}_{3} \mathrm{R}^{\prime} \mathrm{PCl}_{\text {org }} \rightleftharpoons\left(\mathrm{R}_{3} \mathrm{R}^{\prime} \mathrm{P}\right)_{2} \mathrm{CdCl}_{4 \text { org }} \\
\mathrm{CuCl}_{2 \mathrm{aq}}+2 \mathrm{R}_{3} \mathrm{R}^{\prime} \mathrm{PCl}_{\text {org }} \rightleftharpoons\left(\mathrm{R}_{3} \mathrm{R}^{\prime} \mathrm{P}\right)_{2} \mathrm{CuCl}_{4 \text { org }}^{2-} \\
\mathrm{CuCl}_{4 \mathrm{aq}}^{2-}+2 \mathrm{R}_{3} \mathrm{R}^{\prime} \mathrm{PCl}_{\text {org }} \rightleftharpoons\left(\mathrm{R}_{3} \mathrm{R}^{\prime} \mathrm{P}\right)_{2} \mathrm{CuCl}_{4 \text { org }}^{2-}+2 \mathrm{Cl}_{\text {org }}^{-}
\end{gathered}
$$

The difference in the extraction behavior of $\mathrm{Cd}(\mathrm{II})$ and $\mathrm{Cu}(\mathrm{II})$ can be attributed to the fact that in chloride solutions cadmium(II) forms mainly stable complexes of the type $\mathrm{CdCl}_{2}$ and $\mathrm{CdCl}_{3}^{-}$at high chloride ions concentrations, while copper(II) exists mainly as $\mathrm{CuCl}_{2}$ and $\mathrm{CuCl}_{4}^{2-}[33,34]$. Further investigations are necessary to confirm these suggested reactions of $\mathrm{Cd}(\mathrm{II})$ and $\mathrm{Cu}(\mathrm{II})$ with the phosphonium ionic liquids.

\subsection{Stripping}

Sulfuric acid solutions were tested to strip $\mathrm{Cd}(\mathrm{II})$ and $\mathrm{Cu}(\mathrm{II})$ from the loaded organic phases at phase volume ratio $\mathrm{A}: \mathrm{O}=1$. Recovery results for various sulfuric acid concentrations as the stripping solutions are presented in Table 1. Examination of this table indicates that sulfuric acid leads to high $\mathrm{Cd}(\mathrm{II})$ and $\mathrm{Cu}$ (II) stripping efficiency but the stripping of $\mathrm{Cd}(\mathrm{II})$ from the organic phase is not effective with dilute acid. It can be observed that increasing the $\mathrm{H}_{2} \mathrm{SO}_{4}$ concentration causes a significant increase in the $\mathrm{Cd}$ (II) and $\mathrm{Cu}(\mathrm{II})$ stripping efficiency. The most efficient stripping phase of the studied metal ions from Cyphos IL 101 and Cyphos IL 104 seems to be $1 \mathrm{~mol} \cdot \mathrm{dm}^{-3} \mathrm{H}_{2} \mathrm{SO}_{4}$. The stripping of $\mathrm{Cd}(\mathrm{II})$ and $\mathrm{Cu}(\mathrm{II})$ was found to be above 82 and $92 \%$, respectively, in a single contact by $1 \mathrm{~mol} \cdot \mathrm{dm}^{-3} \mathrm{H}_{2} \mathrm{SO}_{4}$ for both extractants. Thus, $1 \mathrm{~mol} \cdot \mathrm{dm}^{-3} \mathrm{H}_{2} \mathrm{SO}_{4}$ was chosen as the receiving solution in the transport process through PIMs. The bonds in the metal-ionic liquid complexes in the organic phase are very strong but the application of $1 \mathrm{~mol} \cdot \mathrm{dm}^{-3}$ $\mathrm{H}_{2} \mathrm{SO}_{4}$ allows the effective removal of $\mathrm{Cd}(\mathrm{II})$ from the organic phase into the aqueous

Table $1 \mathrm{Cd}(\mathrm{II})$ and $\mathrm{Cu}(\mathrm{II})$ stripping efficiencies by sulfuric acid from $0.1 \mathrm{~mol} \cdot \mathrm{dm}^{-3} \mathrm{Cyphos}$ IL 101 and $0.1 \mathrm{~mol} \cdot \mathrm{dm}^{-3}$ Cyphos IL 104 in toluene previously loaded by contacting the extraction solvent with an aqueous phase containing $0.01 \mathrm{~mol} \cdot \mathrm{dm}^{-3} \mathrm{Cd}(\mathrm{II})$ and $0.01 \mathrm{~mol} \cdot \mathrm{dm}^{-3} \mathrm{Cu}(\mathrm{II})$ in $0.1 \mathrm{~mol} \cdot \mathrm{dm}^{-3} \mathrm{HCl}$

\begin{tabular}{lllll}
\hline $\begin{array}{l}\text { Stripping solution } \\
\left(\mathrm{H}_{2} \mathrm{SO}_{4}\right)\left(\mathrm{mol} \cdot \mathrm{dm}^{-3}\right)\end{array}$ & $\begin{array}{l}\text { Stripping } \\
\text { efficiency of } \\
\text { Cd(II) }(\%) \\
\text { Cyphos IL } 101\end{array}$ & $\begin{array}{l}\text { Stripping } \\
\text { efficiency of } \\
\mathrm{Cu}(\mathrm{II})(\%)\end{array}$ & $\begin{array}{l}\text { Stripping } \\
\text { efficiency of } \\
\text { Cd(II) }(\%) \\
\text { Cyphos IL 104 }\end{array}$ & $\begin{array}{l}\text { Stripping } \\
\text { efficiency of } \\
\mathrm{Cu}(\mathrm{II})(\%)\end{array}$ \\
\hline 0.1 & 28.4 & 48.6 & 29.6 & 53.0 \\
0.2 & 35.2 & 52.6 & 38.8 & 57.4 \\
0.5 & 46.8 & 83.2 & 51.5 & 85.7 \\
1.0 & 82.4 & 92.9 & 83.1 & 93.5 \\
\hline
\end{tabular}

Phase volume ratio $\mathrm{O} / \mathrm{A}=1 ; t=25^{\circ} \mathrm{C}$ 
phase. This stripping solution strongly attracts Cd(II) from the ILs; therefore it seems to be a suitable stripping agent in this process.

\subsection{Transport of $\mathrm{Cd}(\mathrm{II})$ and $\mathrm{Cu}(\mathrm{II})$ Through PIMs with Cyphos IL 101 and Cyphos IL 104}

Recently, we have observed that ionic liquids play an increasingly important role in separation techniques, including extractions and membrane processes and are frequently used for separation of metal ions. The membranes used in the present work for studying the transport of $\mathrm{Cd}(\mathrm{II})$ and $\mathrm{Cu}(\mathrm{II})$ were formed by casting CTA from the organic solution containing phosphonium ionic liquid as ion carrier and nitrophenyloctyl ether (ONPOE) to form a thin, stable film. The selectivity and efficiency of the facilitated transport of metal ions from an aqueous solution through PIMs depend on the extraction capability of the carrier. The kind of carrier in the membrane plays a significant role during the permeation of metal ions in transport processes. High process selectivity is achieved when an appropriate carrier is used for synthesis of the membrane. Therefore, the choice and the application of an appropriate ion carrier is very important. To study the influence of the type of carrier in PIM on the facilitated transport process of $\mathrm{Cd}(\mathrm{II})$ and $\mathrm{Cu}(\mathrm{II})$ ions, the PIMs were prepared by using two quaternary phosphonium salts: Cyphos IL 101 and Cyphos IL 104. The ionic liquids contain different anions. The resulting membrane contained 15.6 wt.\% CTA1 and 41.2 wt.\% ion carrier and 43.2 wt.\% ONPOE. Cyphos IL 101 and Cyphos IL 104 have similar densities $\left(d_{\text {Cyphos } 101}=0.880 \mathrm{~g} \cdot \mathrm{cm}^{-3}\right.$ and

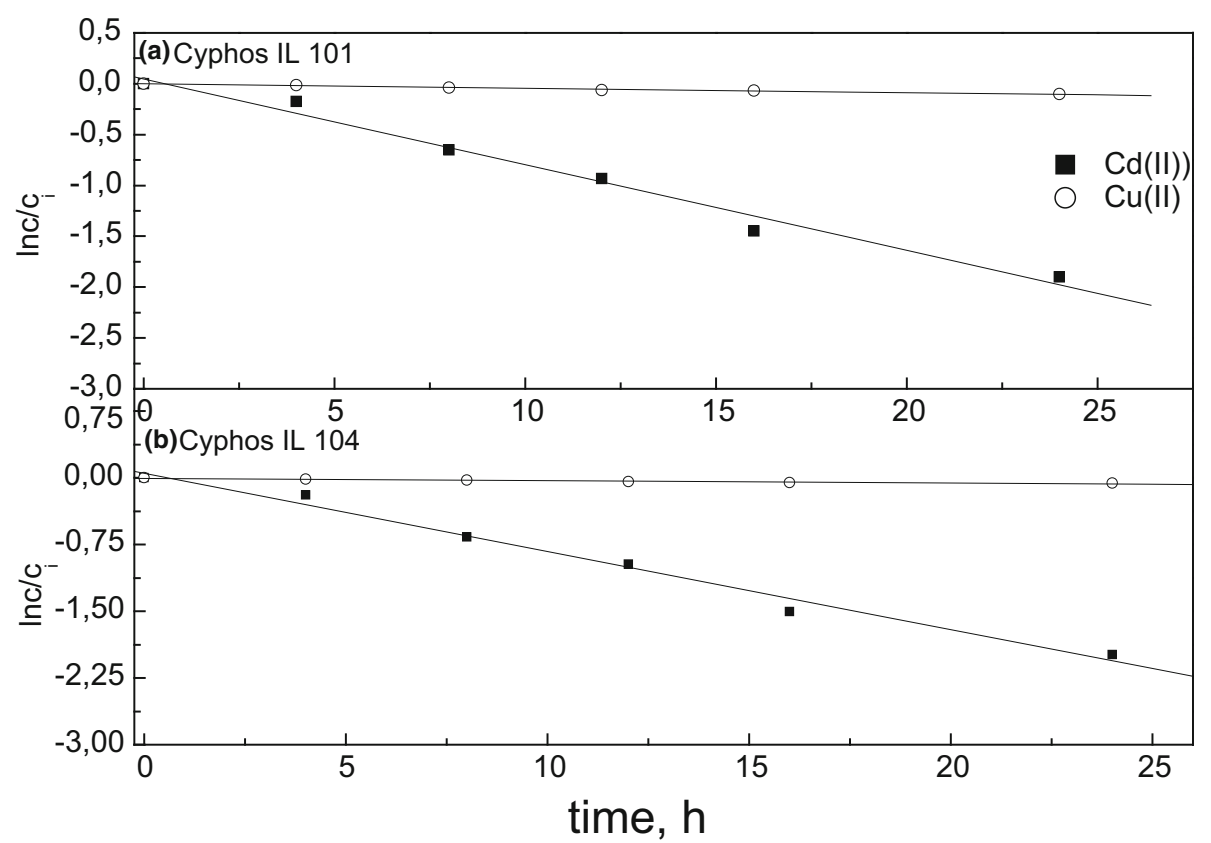

Fig. 3 Plot of $\ln \left(c / c_{i}\right)$ versus time for $\mathrm{Cd}(\mathrm{II})$ and $\mathrm{Cu}(\mathrm{II})$ transport across PIM depending on the kind of ion carrier. PIM: $0.075 \mathrm{~g}$ CTA, $2.7 \mathrm{~cm}^{3}$ ONPOE/ $1 \mathrm{~g}$ CTA, $1.5 \mathrm{~mol} \cdot \mathrm{dm}^{-3}$ ion carrier; the source phase: $0.01 \mathrm{~mol} \cdot \mathrm{dm}^{-3} \mathrm{Cd}(\mathrm{II}), \mathrm{Cu}(\mathrm{II})$ in $0.1 \mathrm{~mol} \cdot \mathrm{dm}^{-3} \mathrm{HCl}$; the receiving phase: $1 \mathrm{~mol} \cdot \mathrm{dm}^{-3} \mathrm{H}_{2} \mathrm{SO}_{4}$ 
$d_{\text {Cyphos } 104}=0.892 \mathrm{~g} \cdot \mathrm{cm}^{-3}$ ). One of the main aims of this work is to study the transport kinetics of $\mathrm{Cd}(\mathrm{II})$ and $\mathrm{Cu}(\mathrm{II})$ across PIMs with Cyphos IL 101 and Cyphos IL 104. The compounds have been chosen as the ion carriers in CTA membranes on the basis of the preliminary studies on solvent extraction.

In preliminary experiments, the transport studies of $\mathrm{Cd}(\mathrm{II})$ and $\mathrm{Cu}$ (II) were carried out from $0.1 \mathrm{~mol} \cdot \mathrm{dm}^{-3} \mathrm{HCl}$ as the source solution into $1 \mathrm{~mol} \cdot \mathrm{dm}^{-3} \mathrm{H}_{2} \mathrm{SO}_{4}$ through PIMs containing Cyphos IL 101 or Cyphos IL 104 as the selective ion carriers. We can expect that anions of the ILs will affect on the permeability of the studied cations. Figure 3 shows the kinetic dependence of $\ln \left(c / c_{i}\right)$ versus time for the transport of $\mathrm{Cd}(\mathrm{II})$ and $\mathrm{Cu}$ (II) through PIMs with different ion carriers. Table 2 shows the variation of the rate constants, the initial fluxes, recovery factors $(R F)$ of $\mathrm{Cd}(\mathrm{II})$ and $\mathrm{Cu}(\mathrm{II})$ after $24 \mathrm{~h}$ and the selectivity coefficients $\left(S_{\mathrm{Cd} / \mathrm{Cu}}\right)$ versus the type of ion carrier in the membrane. The results show that the initial fluxes of metal ions through PIMs with different carriers decrease in the sequence: $\mathrm{Cd}(\mathrm{II})>\mathrm{Cu}$ (II). This means that the anion in the structure of the studied phosphonium ILs does not change the order of selectivity of $\mathrm{Cd}(\mathrm{II})$ over $\mathrm{Cu}$ (II) from $0.1 \mathrm{~mol} \cdot \mathrm{dm}^{-3} \mathrm{HCl}$. However, the higher selectivity coefficient $\left(S_{\mathrm{Cd} / \mathrm{Cu}}\right)$ was obtained for PIM with Cyphos IL 104 as the ion carrier. We observe that the recovery factors and initial fluxes of $\mathrm{Cu}$ (II) through PIMs with both phosphonium ILs are very low, making the transport selectivity of $\mathrm{Cd}(\mathrm{II})$ over $\mathrm{Cu}(\mathrm{II})$ ions very high. The initial fluxes of $\mathrm{Cd}(\mathrm{II})$ and $\mathrm{Cu}(\mathrm{II})$ are 18.8 and $0.67 \mu \mathrm{mol} \cdot \mathrm{m}^{-2} \cdot \mathrm{s}^{-1}$, respectively, for the membrane containing Cyphos IL 104 as ion carrier. As can be seen from Table 2, the recovery factor of Cd(II) was also the highest (above $86 \%$ ) for PIM with Cyphos IL 104. Thus, the PIM with Cyphos IL 104 as carrier was used in the next series of experiments.

\subsection{Effect of Hydrochloric Acid Concentration in the Source Phase}

Cyphos IL 104 was chosen as the selective ion carrier on the basis of the solvent extraction results and the preliminary PIM experiments. The ion carrier was physically immobilized in the polymer matrix containing ONPOE, which was used as the plasticizer as well as solvent for carrier. Hydrochloric acid solutions were used to determine the effect of the acid concentration in the source phase on $\mathrm{Cd}(\mathrm{II})$ and $\mathrm{Cu}$ (II) transport within the PIMs system. In order to investigate the influence of hydrochloric acid concentration in the source phase on the transport of metal ions, the experiments were performed at $\mathrm{HCl}$ concentrations varying from 0.1 to $2.0 \mathrm{~mol} \cdot \mathrm{dm}^{-3}$. Separation of $\mathrm{Cd}(\mathrm{II})$ and $\mathrm{Cu}(\mathrm{I})$ was carried out from the source phase containing $0.01 \mathrm{~mol} \cdot \mathrm{dm}^{-3}$ of each metal ion; $1 \mathrm{~mol} \cdot \mathrm{dm}^{-3} \mathrm{H}_{2} \mathrm{SO}_{4}$ was used as the receiving phase. Figure 4 shows the dependence of the

Table 2 Kinetic parameters for $\mathrm{Cd}(\mathrm{II})$ and $\mathrm{Cu}(\mathrm{II})$ transport across the PIM depending on the kind of ion carrier

\begin{tabular}{|c|c|c|c|c|c|c|c|}
\hline \multirow[t]{2}{*}{ Ion carrier } & \multicolumn{2}{|c|}{$\begin{array}{l}\text { Rate constant } \\
k\left(\mathrm{~h}^{-1}\right)\end{array}$} & \multicolumn{2}{|c|}{$\begin{array}{l}\text { Initial flux } J_{i} \\
\left(\mu \mathrm{mol} \cdot \mathrm{m}^{-2} \cdot \mathrm{s}^{-1}\right)\end{array}$} & \multicolumn{2}{|c|}{$\begin{array}{l}\text { Recovery factor } \\
(\%) \text { (after } 24 \mathrm{~h})\end{array}$} & \multirow[t]{2}{*}{$\begin{array}{l}\text { Selectivity } \\
\text { coefficient } S_{\mathrm{Cd} / \mathrm{Cu}}\end{array}$} \\
\hline & $\mathrm{Cd}(\mathrm{II})$ & $\mathrm{Cu}(\mathrm{II})$ & $\mathrm{Cd}(\mathrm{II})$ & $\mathrm{Cu}(\mathrm{II})$ & $\mathrm{Cd}(\mathrm{II})$ & $\mathrm{Cu}(\mathrm{II})$ & \\
\hline Cyphos IL 101 & 0.084 & 0.004 & 18.0 & 0.97 & 85.1 & 9.7 & 18.5 \\
\hline Cyphos IL 104 & 0.085 & 0.003 & 18.8 & 0.67 & 86.3 & 5.9 & 28.1 \\
\hline
\end{tabular}

PIM: $0.075 \mathrm{~g}$ CTA, $2.7 \mathrm{~cm}^{3}$ ONPOE/1 g CTA, $1.5 \mathrm{~mol} \cdot \mathrm{dm}^{-3}$ ion carrier; the source phase: $0.01 \mathrm{~mol} \cdot \mathrm{dm}^{-3}$ $\mathrm{Cd}(\mathrm{II}), \mathrm{Cu}(\mathrm{II})$ in $0.1 \mathrm{~mol} \cdot \mathrm{dm}^{-3} \mathrm{HCl}$; the receiving phase: $1 \mathrm{~mol} \cdot \mathrm{dm}^{-3} \mathrm{H}_{2} \mathrm{SO}_{4}$ 
permeability coefficient $(P)$ of the cations transported on the $\mathrm{HCl}$ concentration. As can be seen from this figure, the permeability coefficient of $\mathrm{Cd}(\mathrm{II})$ increased with $\mathrm{HCl}$ concentration in the source phase from $1.88 \mu \mathrm{m} \cdot \mathrm{s}^{-1}$ at $0.1 \mathrm{~mol} \cdot \mathrm{dm}^{-3} \mathrm{HCl}$ to $2.53 \mu \mathrm{m} \cdot \mathrm{s}^{-1}$ at $2 \mathrm{~mol} \cdot \mathrm{dm}^{-3} \mathrm{HCl}$. The dependence for the transport of $\mathrm{Cu}(\mathrm{II})$ is very similar but the increase of the permeability coefficient values is slightly lower. As can be seen from this figure, the permeability coefficient of $\mathrm{Cu}$ (II) increased with $\mathrm{HCl}$ concentration, increasing from $0.067 \mu \mathrm{m} \cdot \mathrm{s}^{-1}$ at $0.1 \mathrm{~mol} \cdot \mathrm{dm}^{-3} \mathrm{HCl}$ to $0.211 \mu \mathrm{m} \cdot \mathrm{s}^{-1}$ at $2 \mathrm{~mol} \cdot \mathrm{dm}^{-3} \mathrm{HCl}$ as the source phase. It appears that an increase in hydrochloric acid concentration is responsible for an increase in the permeability coefficient of $\mathrm{Cd}(\mathrm{II})$, likely due to the presence of anionic species, mainly $\mathrm{CdCl}_{3}^{-}$in the source phase. The permeability coefficients calculated for $\mathrm{Cd}(\mathrm{II})$ and $\mathrm{Cu}$ (II) transport from the source phase of various concentrations of hydrochloric acid confirm that PIM transport depends strongly on the acid and chloride ion concentrations in the source phase.

A mathematical model can be proposed in this study for the explanation of permeation kinetics of $\mathrm{Cd}(\mathrm{II})$ and $\mathrm{Cu}(\mathrm{II})$. This model takes into account both the diffusion of Cyphos IL 104 and its ion pair with the chlorocomplexes of the metal ions within the PIM and the kinetics of the interfacial reaction. We can determine the content of metal species in the aqueous chloride solutions on the basis of the theoretical values of chlorocomplexes formation. Table 3 shows species of $\mathrm{Cd}(\mathrm{II})$ and $\mathrm{Cu}$ (II) in the aqueous chloride solutions, calculated from data on chloro-complex stability constants from the literature. The literature values of stability constants for $\mathrm{Cd}(\mathrm{II})$ are the following: $\log _{10} \beta_{1, \mathrm{Cd}}=1.46 ; \log _{10}$ $\beta_{2, \mathrm{Cd}}=1.95 ; \log _{10} \beta_{3, \mathrm{Cd}}=2.17[18,35]$. The values for the $\mathrm{Cu}(\mathrm{II})$ complexes are: $\log _{10}$ $\beta_{1, \mathrm{Cu}}=0.93 ; \log _{10} \beta_{2, \mathrm{Cu}}=0.79 ; \log _{10} \beta_{3, \mathrm{Cu}}=0.46 ; \log _{10} \beta_{4, \mathrm{Cu}}=0.01$ [35]. Table 3 shows the percent molar contributions of chloride complex species $(\%)$ for $\mathrm{Cd}(\mathrm{II})$ and $\mathrm{Cu}(\mathrm{II})$. As can be seen from this table, in the case of $\mathrm{Cd}(\mathrm{II})$, the predominant species of $\mathrm{Cd}(\mathrm{II})$ at $0.1 \mathrm{~mol} \cdot \mathrm{dm}^{-3} \mathrm{Cl}^{-}$is $\mathrm{CdCl}^{+}$, at $0.5 \mathrm{~mol} \cdot \mathrm{dm}^{-3} \mathrm{Cl}^{-}$it is $\mathrm{CdCl}_{2}$ and at 1-2 mol. $\mathrm{dm}^{-3} \mathrm{Cl}^{-}$it is $\mathrm{CdCl}_{3}^{-}$. Therefore, it can be concluded that the permeation of $\mathrm{Cd}(\mathrm{II})$ is better in the presence of a high concentration of chloride ions and anionic

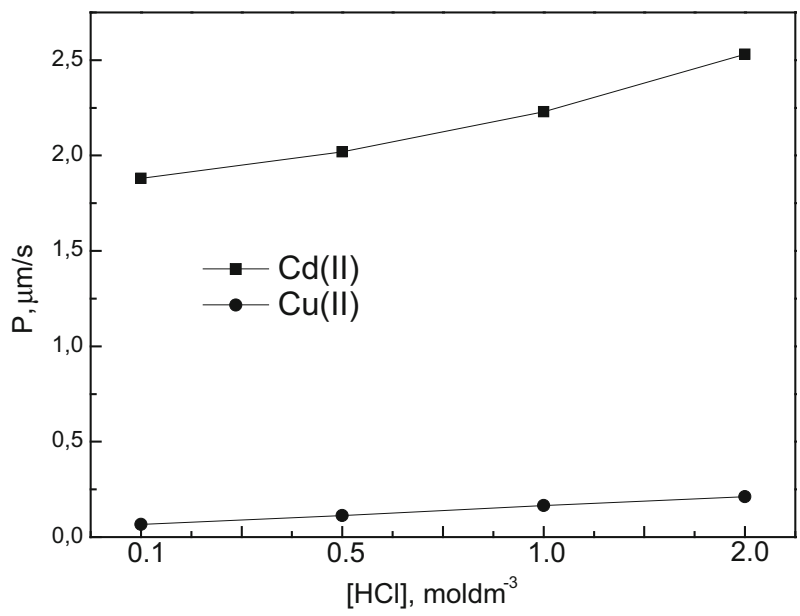

Fig. 4 Effect of $\mathrm{HCl}$ concentration in the source phase on the permeability coefficient $(P)$ of $\mathrm{Cd}(\mathrm{II})$ and $\mathrm{Cu}$ (II) across PIM with Cyphos IL 104. PIM: $0.075 \mathrm{~g} \mathrm{CTA}, 2.7 \mathrm{~cm}^{3}$ ONPOE/1 g CTA, $1.5 \mathrm{~mol} \cdot \mathrm{dm}^{-3}$ Cyphos IL 104; the source phase: $0.01 \mathrm{~mol} \cdot \mathrm{dm}^{-3} \mathrm{Cd}(\mathrm{II}), 0.01 \mathrm{~mol} \cdot \mathrm{dm}^{-3} \mathrm{Cu}(\mathrm{II})$ in $\mathrm{HCl}$; the receiving phase: $\mathrm{mol} \cdot \mathrm{dm}^{-3} \mathrm{H}_{2} \mathrm{SO}_{4}$ 
Table 3 The percent molar contributions of chloride complex species (\%) for Cd(II) and Cu(II) depending on chloride ion concentrations

\begin{tabular}{clccccc}
\hline Metal & {$\left[\mathrm{Cl}^{-}\right]\left(\mathrm{mol} \cdot \mathrm{dm}^{-3}\right)$} & $\mathrm{M}^{2+}(\%)$ & $\mathrm{MCl}^{+}(\%)$ & $\mathrm{MCl}_{2}(\%)$ & $\mathrm{MCl}_{3}^{-}(\%)$ & $\mathrm{MCl}_{4}^{2-}(\%)$ \\
\hline $\mathrm{Cd}(\mathrm{II})$ & 0.1 & 12.3 & 51.4 & 31.2 & 5.1 & - \\
& 0.5 & 1.9 & 26.3 & 52.1 & 19.7 & - \\
& 1.0 & - & 8.5 & 44.3 & 47.2 & - \\
& 2.0 & - & 2.8 & 36.1 & 61.1 & - \\
$\mathrm{Cu}(\mathrm{II})$ & 0.1 & 52.6 & 43.7 & 3.7 & - & - \\
& 0.5 & 16.1 & 58.4 & 20.3 & 5.2 & - \\
& 1.0 & 5.6 & 42.8 & 31.6 & 16.3 & 3.7 \\
& 2.0 & 3.9 & 11.5 & 32.4 & 29.1 & 23.1 \\
\hline
\end{tabular}

chlorocomplexes of $\mathrm{Cd}(\mathrm{II})$, which are more easily transported from the source phase. A similar dependence in the transport of Cd(II) through PIM with Cyphos IL 104 was obtained in the previous study [18]. It can be observed that permeation was very effective for the transport of $\mathrm{Cd}(\mathrm{II})$ from sodium chloride solution as well as from hydrochloric acid solutions, with similar values. On the other hand, the predominant species of $\mathrm{Cu}$ (II) at $0.1 \mathrm{~mol} \cdot \mathrm{dm}^{-3} \mathrm{Cl}^{-}$is $\mathrm{Cu}^{2+}$, at $0.5-1 \mathrm{~mol} \cdot \mathrm{dm}^{-3} \mathrm{Cl}^{-}$is $\mathrm{CuCl}^{+}$and at $2 \mathrm{~mol} \cdot \mathrm{dm}^{-3} \mathrm{Cl}^{-}$ $\mathrm{CuCl}_{2}$ (Table 3). The results obtained from the transport process show that permeation of $\mathrm{Cu}$ (II) was not improved by increasing chloride concentration. The transport of $\mathrm{Cd}(\mathrm{II})$ across the PIM with Cyphos IL 104 is much faster than for $\mathrm{Cu}(\mathrm{II})$, which can be explained by the much higher extraction constant of $\mathrm{Cd}(\mathrm{II})$. Wang et al. [19] reported a similar observation in the transport of $\mathrm{Cd}(\mathrm{II})$ and $\mathrm{Cu}(\mathrm{II})$ from $\mathrm{HCl}$ solutions through $\mathrm{PIM}$ with Aliquat 336 (trioctylmethylammonium chloride), which is also an ionic liquid, quaternary ammonium salt.

Table 4 shows the kinetic parameters of this transport processes. It was observed that the initial fluxes of $\mathrm{Cd}$ (II) and $\mathrm{Cu}$ (II) achieved the highest values of 25.3 and $2.11 \mu \mathrm{mol} \cdot \mathrm{m}^{-2} \cdot \mathrm{s}^{-1}$, respectively, from $2 \mathrm{~mol} \cdot \mathrm{dm}^{-3} \mathrm{HCl}$ as the source phase. The dependence on the recovery factor (\%) of $\mathrm{Cd}(\mathrm{II})$ and $\mathrm{Cu}(\mathrm{II})$ ions from $\mathrm{HCl}$ solutions as the function of the acid concentration is shown in Fig. 5. It was observed that the recovery factor of $\mathrm{Cd}(\mathrm{II})$ and $\mathrm{Cu}(\mathrm{II})$ transport achieved the highest values of 94.3 and $19.4 \%$, respectively, at $2 \mathrm{~mol} \cdot \mathrm{dm}^{-3} \mathrm{HCl}$ in the source phase. As can be observed from Table 3,

Table 4 The initial fluxes, rate constants and selectivity coefficients for competitive transport of Cd(II) and $\mathrm{Cu}(\mathrm{II})$ across PIM with Cyphos IL 104

\begin{tabular}{lllllll}
\hline$[\mathrm{HCl}]\left(\mathrm{mol} \cdot \mathrm{dm}^{-3}\right)$ & \multicolumn{2}{l}{ Rate constant $k\left(\mathrm{~h}^{-1}\right)$} & & \multicolumn{2}{l}{ Initial flux $J_{i}\left(\mu \mathrm{mol} \cdot \mathrm{m}^{-2} \cdot \mathrm{s}^{-1}\right)$} & \multirow{2}{l}{$\begin{array}{l}\text { Selectivity } \\
\text { coefficient } S_{\mathrm{Cd} / \mathrm{Cu}}\end{array}$} \\
\cline { 2 - 3 } & $\mathrm{Cd}(\mathrm{II})$ & $\mathrm{Cu}(\mathrm{II})$ & & $\mathrm{Cd}(\mathrm{II})$ & $\mathrm{Cu}(\mathrm{II})$ & \\
\hline 0.1 & 0.085 & 0.003 & & 18.8 & 0.67 & 28.1 \\
0.5 & 0.091 & 0.005 & & 20.2 & 1.13 & 17.9 \\
1 & 0.101 & 0.007 & & 22.3 & 1.65 & 13.5 \\
2 & 0.114 & 0.009 & & 25.3 & 2.11 & 11.2 \\
\hline
\end{tabular}

PIM: $\quad 0.075 \mathrm{~g}$ CTA, $2.7 \mathrm{~cm}^{3}$ ONPOE/1 g CTA, $1.5 \mathrm{~mol} \cdot \mathrm{dm}^{-3}$ Cyphos 104; the source phase: $0.01 \mathrm{~mol} \cdot \mathrm{dm}^{-3} \mathrm{Cd}(\mathrm{II}), 0.01 \mathrm{~mol} \cdot \mathrm{dm}^{-3} \mathrm{Cu}$ (II) in $\mathrm{HCl}$; the receiving phase: $1 \mathrm{~mol} \cdot \mathrm{dm}^{-3} \mathrm{H}_{2} \mathrm{SO}_{4}$ 
the selectivity coefficient for $\mathrm{Cd}(\mathrm{II})$ over $\mathrm{Cu}$ (II) decreases with $\mathrm{HCl}$ concentration increasing in the source phase from 28.1 for $0.1 \mathrm{~mol} \cdot \mathrm{dm}^{-3} \mathrm{HCl}$ to $11.2 \mathrm{for} 2 \mathrm{~mol} \cdot \mathrm{dm}^{-3}$ $\mathrm{HCl}$. Guo et al. [31] reported also the effect of $\mathrm{HCl}$ concentration in the source phase on $\mathrm{Cr}(\mathrm{VI})$ transport through PIM with Cyphos IL 104 and obtained a similar dependence. They observed that with $\mathrm{HCl}$ concentration increasing in the feed phase, the initial flux of $\mathrm{Cr}(\mathrm{VI})$ also increased. Comesana et al. [34] showed the transport of $\mathrm{Cd}(\mathrm{II})$ from $\mathrm{HCl}$ solution by non-dispersive solvent extraction with strip dispersion (NDSXSD) using Cyphos IL 101. They observed decreasing Cd(II) permeation when the hydrochloric acid concentration of the source phase is decreased.

\subsection{Effect of Chloride Ion Concentration in the Source Phase}

The influence of chloride ion concentration on the initial flux $\left(J_{i}\right)$ of $\mathrm{Cd}(\mathrm{II})$ and $\mathrm{Cu}$ (II) was investigated. The experiments were carried out at various chloride concentrations provided by sodium chloride. The concentration of chloride ions $\left[\mathrm{Cl}^{-}\right]$was varied between 0.1 and $2 \mathrm{~mol} \cdot \mathrm{dm}^{-3}$. The results are presented in Fig. 6. This figure shows changes of the permeability coefficients of metal ions with chloride concentration in the source phase. As can be observed from this figure, when the chloride ions concentration increases, the values of the permeability coefficients also increase for both metal ions. The permeability coefficients of $\mathrm{Cd}(\mathrm{II})$ and $\mathrm{Cu}(\mathrm{II})$ reached the highest values of 2.75 and $1.52 \mu \mathrm{m} \cdot \mathrm{s}^{-1}$, respectively, at $2 \mathrm{~mol} \cdot \mathrm{dm}^{-3}$ chloride in the source solution. It can be observed that the transport of $\mathrm{Cd}(\mathrm{II})$ was very effective from highly saline media. Similar dependences in the transport of $\mathrm{Cd}(\mathrm{II})$ and $\mathrm{Cu}(\mathrm{II})$ through the PIM with Cyphos IL 104 were obtained from hydrochloric acid solutions but the obtained values of permeability coefficients are higher in the case of transport of metal ions from sodium chloride solutions. We can see that permeation was more effective for the transport of $\mathrm{Cd}(\mathrm{II})$ than $\mathrm{Cu}$ (II) from sodium chloride solutions as well as from hydrochloric acid solutions.

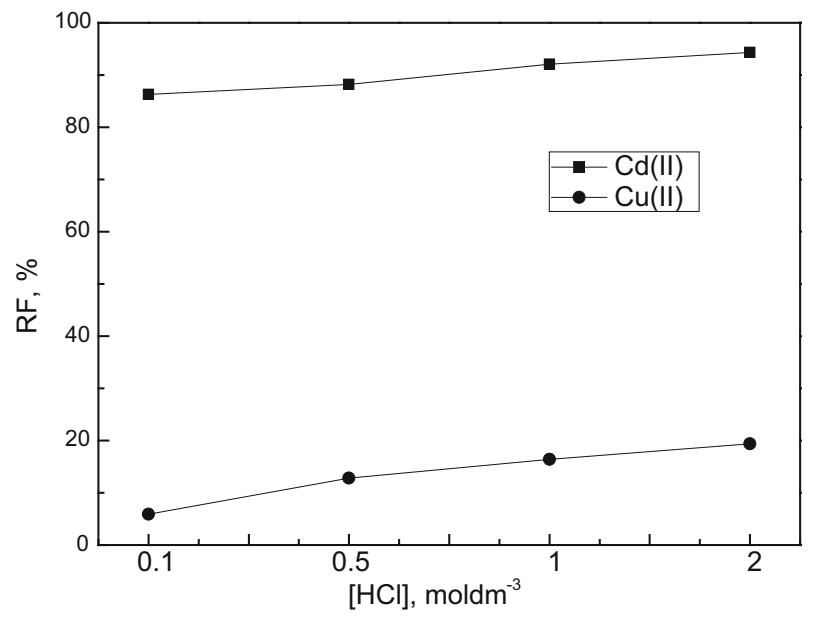

Fig. 5 Relation of recovery factor $[R F(\%)]$ of $\mathrm{Cd}(\mathrm{II})$ and $\mathrm{Cu}(\mathrm{II})$ after $24 \mathrm{~h}$ versus $\mathrm{HCl}$ concentration in the source phase. Experimental conditions as in Table 3 


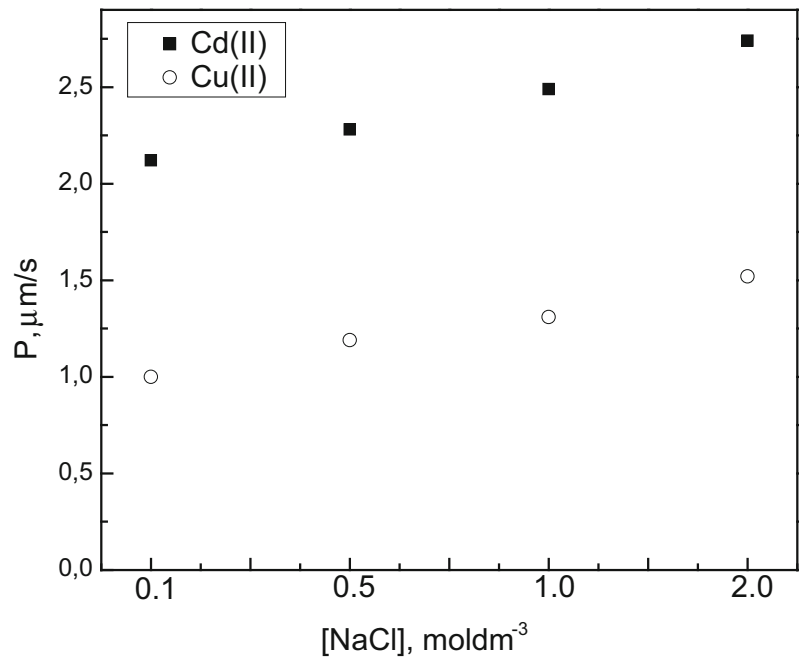

Fig. 6 The permeability coefficient $(P)$ of $\mathrm{Cd}(\mathrm{II})$ and $\mathrm{Cu}(\mathrm{II})$ versus chloride concentration in the source phase from NaCl solutions. PIM: $1.5 \mathrm{~mol} \cdot \mathrm{dm}^{-3}$ Cyphos IL 104, $2.7 \mathrm{~cm}^{3}$ ONPOE/1 $\mathrm{g}$ CTA; the source phase: $0.01 \mathrm{~mol} \cdot \mathrm{dm}^{-3} \mathrm{Cd}(\mathrm{II})$ and $0.01 \mathrm{~mol} \cdot \mathrm{dm}^{-3} \mathrm{Cu}(\mathrm{II})$; the receiving phase: $1 \mathrm{~mol} \cdot \mathrm{dm}^{-3} \mathrm{H}_{2} \mathrm{SO}_{4}$

Figure 7 presents the selectivity of this transport process. As can be seen, the selectivity coefficient $\left(S_{\mathrm{Cd} / \mathrm{Cu}}\right)$ of $\mathrm{Cd}$ (II) over $\mathrm{Cu}$ (II) decreases in neutral medium when the chloride ions concentration increases. The highest separation coefficient $\left(S_{\mathrm{Cd} / \mathrm{Cu}}\right)$ was obtained at the lowest sodium chloride concentration, i.e., $0.1 \mathrm{~mol} \cdot \mathrm{dm}^{-3} \mathrm{NaCl}$. The successful separation of metal ions across the membrane is dependent on the chloride ions concentration in the source phase and chemical forms of metal ion in this solution. Adelung et al. [36] and Upitis et al. [20] also studied the separation of $\mathrm{Cd}(\mathrm{II})$ and $\mathrm{Cu}$ (II) from chloride solutions by transport across PIM with the quaternary ammonium salt-Aliquat 336. They reported that

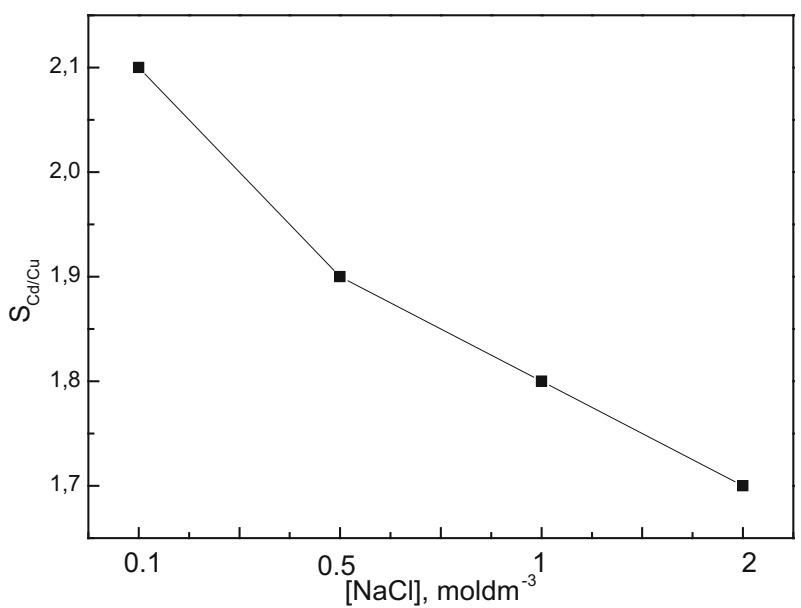

Fig. 7 The selectivity coefficient of $\mathrm{Cd}(\mathrm{II})$ over $\mathrm{Cu}$ (II) versus $\mathrm{NaCl}$ concentration. Experimental conditions as in Fig. 6 
the formation of negatively charged metal chloride complex species was responsible for the extraction of the target metal to PIMs. Experimental results further confirm that the transport selectivity between $\mathrm{Cd}(\mathrm{II})$ and $\mathrm{Cu}$ (II) can be controlled by regulating the chloride concentration of the source phase.

\section{Conclusions}

Results of the presented investigations prove that Cyphos IL 101 and Cyphos IL 104 in toluene can be successfully used as the extractants for $\mathrm{Cd}(\mathrm{II})$ removal from chloride media. Extraction of Cd(II) is very fast and efficient (over $99 \%$ ). The presence of $\mathrm{HCl}$ in the feed enhances $\mathrm{Cd}$ (II) and $\mathrm{Cu}$ (II) extraction and decreases the selectivity coefficient for $\mathrm{Cd}(\mathrm{II})$ over $\mathrm{Cu}(\mathrm{II})$. The obtained results allow the conclusion that the transport process across PIMs with Cyphos IL 104 as the ion carrier provides an attractive alternative to conventional solvent extraction methods for the separation of $\mathrm{Cd}(\mathrm{II})$ and $\mathrm{Cu}$ (II) from hydrochloric acid solutions. The studied PIMs with phosphonium ILs can be recommended for the separation of $\mathrm{Cd}(\mathrm{II})$ and $\mathrm{Cu}(\mathrm{II})$ from hydrochloric acid solutions with regard to the high values of separation coefficients. The higher selectivity coefficient of $\mathrm{Cd}(\mathrm{II})$ over $\mathrm{Cu}$ (II) from $0.1 \mathrm{~mol} \cdot \mathrm{dm}^{-3} \mathrm{HCl}$ as the source phase, was obtained using membranes with Cyphos IL 104. It was found that the initial fluxes of $\mathrm{Cd}$ (II) and $\mathrm{Cu}$ (II) are the highest for $2 \mathrm{~mol} \cdot \mathrm{dm}^{-3} \mathrm{HCl}$ as the source solution and are 25.3 and $2.11 \mu \mathrm{mol} \cdot \mathrm{m}^{-2} \cdot \mathrm{s}^{-1}$, respectively. However, the separation coefficients decrease with increasing $\mathrm{HCl}$ concentration in the source phase, from 28.1 at $0.1 \mathrm{~mol} \cdot \mathrm{dm}^{-3} \mathrm{HCl}$ to 11.2 at $2 \mathrm{~mol} \cdot \mathrm{dm}^{-3} \mathrm{HCl}$. The selectivity of this metal ions transport decreased also in neutral media when the chloride ions concentration increased. The transport process through the PIM containing $15.6 \mathrm{wt}$ \% CTA and 41.2 wt.\% Cyphos IL 104 and 43.2 wt.\% ONPOE enabled extraction above $86 \%$ of $\mathrm{Cd}(\mathrm{II})$ from $0.1 \mathrm{~mol} \cdot \mathrm{dm}^{-3}$ hydrochloric acid into $1 \mathrm{~mol} \cdot \mathrm{dm}^{-3} \mathrm{H}_{2} \mathrm{SO}_{4}$ after $24 \mathrm{~h}$. Finally, the separation membrane system presented in this paper can be useful for the separation of $\mathrm{Cd}(\mathrm{II})$ and $\mathrm{Cu}$ (II) from hydrochloric acid solutions.

Acknowledgments Author thanks Cytec Industries Inc. for providing free samples of Cyphos IL.

Open Access This article is distributed under the terms of the Creative Commons Attribution 4.0 International License (http://creativecommons.org/licenses/by/4.0/), which permits unrestricted use, distribution, and reproduction in any medium, provided you give appropriate credit to the original author(s) and the source, provide a link to the Creative Commons license, and indicate if changes were made.

\section{References}

1. Cote, G.: Hydrometallurgy of strategic metals. Solvent Extr. Ion Exch. 18, 703-727 (2000)

2. Kolodynska, D., Hubicka, H., Hubicki, Z.: Sorption of heavy metal ions from aqueous in the presence of EDTA on monodisperse anion exchangers. Desalination 227, 150-166 (2008)

3. Kumbasar, R.A.: Extraction and concentration study of cadmium from zinc plant leach solutions by emulsion liquid membrane using tioctylamine as extractant. Hydrometallurgy 95, 290-296 (2009)

4. De San Miguel, E.R., Monroy-Baretto, M., Aguilar, J.C., Ocampo, A.L., Gyves, J.: Structural effects on metal ion migration across polymer inclusion membranes: Dependence on membrane properties and transport profiles on the weight and volume fractions of the components. J. Membr. Sci. 379, 416-425 (2011) 
5. Radzyminska-Lenarcik, E., Ulewicz, M.: The use of 1-alkylimidzoles for selective separation of zinc ions in the transport process across a polymeric inclusion membrane. Physicochem. Probl. Miner. Process. 51, 131-142 (2014)

6. Liu, X., Bouchard, G., Miller, N., Galland, A., Girault, H., Testa, B., Carrupt, P.A.: Solvatochromic analysis of partition coefficients in the $o$-nitrophenyl octyl ether (o-NPOE)/water system. Helv. Chim. Acta 86, 3533-3547 (2003)

7. Benosmane, N., Hamdi, S.M., Hamdi, M., Boutemeur, B.: Selective transport of metal ions across polymer inclusion membranes (PIMs) containing calix[4] resorcinarenes. Sep. Purif. Technol. 65, 211-219 (2009)

8. Arous, O., Amara, M., Trari, M., Bouguelia, A., Kerdjoudj, H.: Cadmium(II) and lead(II) transport in a polymer inclusion membrane using tributyl phosphate as mobile carrier and $\mathrm{CuFeO}_{2}$ as a polarized photo electrode. J. Hazard Mater. 180, 493-498 (2010)

9. Kozlowski, C.A., Walkowiak, W.: Applicability of liquid membranes in chromium(VI) transport with amines as ion carriers. J. Membr. Sci. 226, 143-150 (2005)

10. Kebiche-Senhadji, O., Tingry, S., Seta, P., Benamor, M.: Selective extraction of Cr(VI) over metallic species by polymer inclusion membrane (PIM) using anion (Aliquat 336) as carrier. Desaliantion 258, 59-65 (2010)

11. Arous, O., Saoud, F.S., Amara, M., Kerdjoudj, H.: Efficient facilitated transport of lead and cadmium across a plasticized triacetate membrane mediated by D2EHPA and TOPO. Mater. Sci. Appl. 2, 615-623 (2011)

12. Pospiech, B., Walkowiak, W.: Studies on iron(III) removal from chloride aqueous solutions by solvent extraction and transport through polymer inclusion membranes with D2EHPA. Physicochem. Probl. Miner. Process. 44, 195-204 (2010)

13. Gega, J., Otrembska, P.: Separation of Ni(II) and Cd(II) ions with supported liquid membranes (SLM) using D2EHPA as a carrier. Sep. Sci. Technol. 49, 1756-1760 (2014)

14. Pospiech, B.: Synergistic solvent extraction and transport of $\mathrm{Zn}$ (II) and $\mathrm{Cu}(\mathrm{II})$ across polymer inclusion membranes with a mixture of TOPO and Aliquat 336. Sep. Sci. Technol. 49, 1706-1712 (2014)

15. Pospiech, B.: Hydrometallurgical recovery of cobalt(II) from acidic chloride solutions by transport through polymer inclusion membranes. Physicochem. Probl. Miner. Process. 49, 641-649 (2013)

16. Pospiech, B.: Separation of silver(I) and copper(II) from aqueous solutions by transport through polymer inclusion membranes with Cyanex 471X. Sep. Sci. Technol. 47, 1413-1419 (2012)

17. Pospiech, B.: Highly efficient facilitated membrane transport of palladium(II) ions from hydrochloric acid solutions through plasticizer membranes with Cyanex 471X. Physicochem. Probl. Miner. Process. 51, 281-291 (2015)

18. Pospiech, B.: Studies on extraction and permeation of cadmium(II) using Cyphos IL 104 as selective extractant and ion carrier. Hydrometallurgy 154, 88-94 (2015)

19. Wang, L., Paimin, R., Cattrall, R.W., Shen, W., Kolev, S.D.: The extraction of cadmium(II) and copper(II) from hydrochloric acid solutions using an Aliquat 336/PVC membrane. J. Membr. Sci. 176, 105-111 (2000)

20. Upitis, A., Peterson, J., Lukey, Ch., Nghiem, L.D.: Metallic ion extraction using polymer inclusion membranes (PIMs): optimising physical strength and extraction rate. Desalin. Water Treat. 6, 41-47 (2009)

21. Juang, R.S., Kao, H.Ch., Wu, W.H.: Analysis of liquid membrane extraction of binary Zn(II) and Cd(II) from chloride media with Aliquat 336 based on thermodynamic equilibrium models. J. Membr. Sci. 228, 169-177 (2004)

22. Pont, N., Salvado, V., Fontas, C.: Selective transport and removal of $\mathrm{Cd}$ from chloride solutions by polymer inclusion membranes. J. Membr. Sci. 318, 340-345 (2008)

23. Pospiech, B.: Selective recovery of cobalt(II) towards lithium(I) from chloride media by transport across polymer inclusion membrane with triisooctylamine. Pol. J. Chem. Technol. 16, 15-20 (2014)

24. Domanska, U., Rekawek, A.: Extractions of metal ions from aqueous solutions using imidazolium based ionic liquids. J. Solution Chem. 38, 739-751 (2009)

25. Lee, J.M.: Extraction of noble metal ions from aqueous solution by ionic liquids. Fluid Phase Equilib. 319, 30-36 (2012)

26. Cholico Gonzalez, D., Avila-Rodriguez, M., Reyes-Aguilerad, J.A., Cote, G., Chagnes, A.: Rheological behaviour of Cyphos IL101-Cyanex 272 binary mixtures between $288.15 \mathrm{~K}$ and $343.15 \mathrm{~K}$. J. Mol. Liq. 169, 27-32 (2012)

27. De los Rios, A.P., Hernandez-Fernandez, F.J., Alguacil, F.J., Lozano, L.J., Ginesta, A., Garcia-Diaz, I., Sanchez-Segado, S., Lopez, F.A., Godinez, C.: On the use of imidazolium and ammonium-based ionic liquids as green solvents for the selective recovery of $\mathrm{Zn}(\mathrm{II}), \mathrm{Cd}(\mathrm{II}), \mathrm{Cu}(\mathrm{II})$ and $\mathrm{Fe}(\mathrm{III})$ from hydrochloride aqueous solutions. Sep. Purif. Technol. 97, 150-157 (2012) 
28. Regel-Rosocka, M., Wisniewski, M.: Selective removal of zinc(II) from spent pickling solutions in the presence of iron ions with phosphonium ionic liquid Cyphos IL 101. Hydrometallurgy 110, 85-90 (2011)

29. Regel-Rosocka, M., Nowak, L., Wisniewski, M.: Removal of Zn(II) and iron ions from chloride solutions with phosphonium ionic liquids. Sep. Purif. Technol. 9, 158-163 (2012)

30. Kogelnig, D., Regelsberger, A., Stojanovic, A., Jirsa, F., Krachler, R., Keppler, B.K.: A polymer inclusion membrane based on the ionic liquid trihexyl(tetradecyl)phosphonium chloride and PVC for solid-liquid extraction of Zn(II) from hydrochloric acid solution. Monatsh. Chem. 142, 769-772 (2011)

31. Guo, L., Liu, Y., Zhang, C., Chen, J.: Preparation of PVDF-based polymer inclusion membrane using ionic liquid plasticizer and Cyphos IL 104 carrier for Cr(VI) transport. J. Membr. Sci. 372, 314-321 (2011)

32. Pospiech, B., Chagnes, A.: Highly selective solvent extraction of $\mathrm{Zn}$ (II) and $\mathrm{Cu}(\mathrm{II})$ from acidic aqueous chloride solutions with mixture of Cyanex 272 and Aliquat 336. Sep. Sci. Technol. 50, 1302-1309 (2015). doi:10.1080/01496395.2014.967777

33. Rybka, P., Regel-Rosocka, M.: Nickel(II) and cobalt(II) extraction from chloride solutions with quaternary phosphonium salts. Sep. Sci. Technol. 47, 1296-1302 (2012)

34. Comesana, A., Rodriguez-Monsalve, J., Cerpa, A., Alguacil, F.J.: Non-dispersive solvent extraction with strip dispersion (NDSXSD) pertraction of $\mathrm{Cd}(\mathrm{II})$ in $\mathrm{HCl}$ medium using ionic liquid CYPHOS IL 101. Chem. Eng. J. 175, 228-232 (2011)

35. Högfeldt, E.: Stability Constants of Metal-Ion Complexes, Part A: Inorganic Ligands. Pergamon Press, Oxford (1982)

36. Adelung, S., Lohrengel, B., Nghiem, L.D.: Selective transport of cadmium by PVC/Aliquat 336 polymer inclusion membranes (PIMs): the role of membrane composition and solution chemistry. Membr. Water Treat. 3, 123-131 (2012) 